\title{
Resíduos alimentares do lixo domiciliar: Estudo do uso na alimentação de frangos de corte ${ }^{1}$
}

\author{
Ednilson Viana ${ }^{2}$, Harry E. Schulz ${ }^{2}$, Ricardo Albuquerque ${ }^{3} \&$ Adriana B. Noronha $^{4}$
}

\begin{abstract}
RESUMO
O trabalho foi elaborado com o propósito de se avaliar o uso de resíduos alimentares na ração de frangos de corte, obtidos através de coleta seletiva em um bairro popular da cidade de São Carlos, SP, Brasil, triturados, esterilizados, secados e caracterizados química e microbiologicamente. O componente final obtido, denominado Ingrediente de Ração dos Resíduos Alimentares (IRRA), foi testado em frangos como ingrediente de ração, nas proporções de 5, 10, 15, 20 e 25\%, em associação com o farelo de milho, farelo de soja e outros ingredientes. A caracterização do IRRA mostrou ausência de micotoxinas, metais pesados, pesticidas organoclorados e microrganismos patogênicos. Houve valor da energia metabolizável alto $\left(3.483 \mathrm{kcal} \mathrm{kg}^{-1}\right)$, bom valor proteico $(12 \%)$ e diversos minerais. Detectaram-se baixos conteúdos de vitaminas, alguns minerais e aminoácidos. Os resultados mostraram que a inclusão do IRRA em até 20\%, não alterou o desempenho das aves, como avaliado pelos índices de consumo de ração, o ganho de peso e a conversão alimentar.
\end{abstract}

Palavras-chave: reciclagem, ração, nutrição animal, resíduos sólidos, resíduos orgânicos

\section{Food residues of domestic waste: Case study of use in broiler chickens feeding}

\begin{abstract}
The purpose of this study was to evaluate the use of leftover food as chicken feed destined for poultry farms, obtained through selective collection in a popular neighborhood in the city of São Carlos, SP, Brazil, ground up, sterilized, dried and characterized chemically and microbiologically. The final component, called food leftover feed ingredient (FLFI), was tested on chickens as a chicken feed ingredient in proportions of 5, 10, 15, 20 and 25\% mixed with corn and soybean bran and other ingredients. The characterization of the FLFI revealed the absence of mycotoxins, heavy metals, organochlorined pesticides and pathogenic microorganisms. The product showed a high metabolizable energy value $\left(3.483 \mathrm{kcal} \mathrm{kg}^{-1}\right)$, good protein value $(12 \%)$ and various minerals. The vitamin content was found to be low, as were some minerals and amino acids. The results revealed that the inclusion of up to $20 \%$ of FLFI did not modify the chickens' performance, as indicated by the indices of feed consumption, weight gain and food conversion.
\end{abstract}

Key words: recycling, feed, wastelage, food residue, broiler chickens

${ }^{1}$ Tese de Doutorado apresentado na Escola de Engenharia de São Carlos/USP - Campus São Carlos

${ }^{2}$ Escola de Engenharia de São Carlos-USP, Departamento de Hidráulica e Saneamento. Av. Trabalhador São Carlense, n. 400, Centro, São Carlos, SP, CEP 13566-590 - Fone: (48) 9904-4421. E-mail: edv@unesc.rct-sc.br; Fone: (16) 273-9571. E-mail: heschulz@usp.sc.br

${ }^{3}$ Faculdade de Zootecnia e Medicina Veterinária, USP - Campus de Pirassununga, Departamento de Produção Animal. Av. Professor Dr. Orlando Marques de Paiva 87 - CEP 05508-900 - Fone: (19) 561-6215. E-mail: rialbuq@usp.br

${ }_{4}^{4}$ Faculdade de Economia e Administração de Ribeirão Preto - USP, Av. Bandeirantes 3900, Vista Alegre, Ribeirão Preto, SP, CEP 14040-900. Fone: (16) 6023921. E-mail: backx@usp.br 


\section{INTRODUÇÃO}

O termo "resíduos alimentares”, refere-se aos resíduos orgânicos originados do preparo da alimentação humana, seja ele na cozinha da residência ou em qualquer outro tipo de estabelecimento. Esses resíduos são fartamente encontrados nos resíduos sólidos domiciliares, em proporções de até 65\% dos orgânicos totais; já os orgânicos "não alimentares” são compostos por folhas e galhos de árvores, restos de poda de jardim etc., e representam a menor porção dos orgânicos, ou seja, apenas 35\%.

De modo geral, a predominância dos resíduos orgânicos é verificada também com relação aos problemas ambientais e de saúde da população que causam (Schalch, 1984; Freitas, 1996; Simabuco, 1996) de vez que, quando dispostos a céu aberto, como é o caso dos lixões que predominam no País, tornam-se focos de criação de animais vetores de doenças como o rato, mosquito, barata etc e de contaminação de corpos d’água, pelo chorume (Jardim, 1995).

Outro fator a se considerar são os custos de limpeza dos recicláveis quando em contato com os resíduos orgânicos e a diminuição do tempo de vida útil dos aterros sanitários, que deveriam ser ocupados apenas pelos resíduos que não têm condições de serem reciclados ou reaproveitados. Somente a reciclagem da fração orgânica já proporcionaria redução de pelo menos $50 \%$ dos resíduos destinados a tais métodos de disposição.

Por outro lado, a reciclagem da fração orgânica do lixo conta, hoje, com diversas metodologias, com maior ou menor grau de execução, mas que poderiam estar solucionando melhor esta questão. A compostagem, como uma dessas alternativas, trata da produção do composto em que a composição de nutrientes desse tipo de componente serve para o cultivo de plantas; outra alternativa é o uso de tais resíduos orgânicos na alimentação animal.

Apesar de antigo, o uso dos resíduos alimentares na alimentação animal sob a forma popular de "lavagem", tem sido uma conduta que vem sendo aprimorada recentemente, desenvolvida nos últimos 50 anos por agricultores da Europa e Estados Unidos (Lima, 1995). Dentro deste contexto, Pinevich \& Versilin citado por Lima (1995), prepararam uma ração a partir de resíduos vegetais e esterco digerido, sendo que, nos testes realizados com suínos, não foram observados quaisquer surtos de doenças nem anormalidades no desenvolvimento dos animais.

Um outro estudo relevante no reaproveitamento de resíduos diz respeito à silagem de aves mortas para alimentação animal (Oliveira, 1996). Neste estudo, as aves mortas foram submetidas a um processo fermentativo (Blake \& Donald, 1992), secagem (digestor) e prensagem para retirada do excesso de gordura. O componente obtido, denominado Farinha de Silagem de Frango (FSF), foi testado em frangos de corte como ingrediente de ração em até 10\% na composição da ração das aves. Os resultados mostraram que a adição de FSF não afetou a conversão alimentar dessas aves, indicando a sua viabilidade como componente nutritivo para esses animais.

De outra forma, a utilização dos resíduos alimentares que compõem os resíduos orgânicos, busca disponibilizar os nutrientes ali contidos para serem aproveitados pelo metabolismo animal, como tem evidenciado a prática dos lavageiros para a alimentação do porco e da galinha, desde épocas remotas. Esta prática tem demonstrado o potencial nutricional desses resíduos mas deixa, também, muitas dúvidas quanto à sua seguridade, em termos de componentes tóxicos como metais pesados, pesticidas e microrganismos patogênicos. A durabilidade dos resíduos em uso ainda é consideravelmente curta.

É com base na necessidade de se conhecer mais profundamente as características e segurança no uso dos resíduos alimentares na alimentação animal, que se propõe este trabalho buscando-se, inclusive, obter um componente com maior estabilidade e que possa ser armazenado por períodos mais longos, contribuindo assim para a redução dos orgânicos no lixo domiciliar.

\section{MATERIAL E MÉTODOS}

A metodologia utilizada neste trabalho envolveu uma série de etapas consecutivas, tais como: coleta seletiva dos resíduos, processamento, caracterização do componente e formulação de uma ração para frangos de corte, em associação com o farelo de milho e o farelo de soja. Essas etapas são descritas a seguir.

\section{Coleta seletiva e processamento}

A coleta seletiva dos resíduos alimentares do lixo domiciliar foi feita em um bairro de classe popular (Santa Felícia) da cidade de São Carlos, SP, no período de 60 dias.

Os resíduos foram coletados no período da manhã e processados no Laboratório de Resíduos Sólidos da Escola



Figura 1. Triturador utilizado no processamento dos resíduos alimentares do lixo 
de Engenharia de São Carlos, USP, onde eram pesados (avaliação quantitativa) e processados através de trituração em triturador desintegrador/picador (Figura 1). A massa obtida neste processo foi autoclavada a uma temperatura de $121^{\circ} \mathrm{C}$, durante 15 min, e submetida a secagem, em estufa com ventilação forçada a $60{ }^{\circ} \mathrm{C}$ por $24 \mathrm{~h}$ e depois ao sol, por 3 dias. $\mathrm{O}$ material resultante da secagem foi denominado Ingrediente de Ração dos Resíduos Alimentares (IRRA) e submetido às análises químicas e microbiológicas.

\section{Análises químicas e microbiológicas}

As análises químicas efetuadas para o IRRA envolveram as análises de micotoxinas, metais pesados, pesticidas organoclorados, vitaminas e aminoácidos, análises bromatológicas e energia metabolizável, descritas a seguir, de forma sucinta.

a) Análise de micotoxinas: Dentre todas as micotoxinas hoje conhecidas, as mais prejudiciais à avicultura são as aflatoxinas (B1, B2, G1 e G2). A metodologia empregada na análise de aflatoxinas foi o método II, descrito pela AOAC (1984) e modificado por Sabino (1989).

b) Análise de metais pesados: Fez-se esta análise para os metais níquel, cádmio, chumbo e cromo, seguindo a metodologia descrita por Malavolta et al. (1989).

c) Análise de pesticidas organoclorados: Rastrearam-se os seguintes pesticidas: Endrin, Endosulfan I, Endosulfan II, Endosulfan Sulfato, 4,4' - DDD ou TDE (tetraclorodifeniletano), 4,4' - DDT (diclorodifeniltricloroetano), Endrin Aldeído, Metoxicloro, Lindano, Heptacloro, Aldrin, Heptacloro Epóxido, 4,4' - DDE (diclorodifeniletano) e Dieldrin. A metodologia utilizada foi a descrita pela AOAC (1975).

d) Análise de vitaminas e aminoácidos: A análise de vitaminas foi feita para as vitaminas B1, B2, B6, PP, A, betacaroteno, alfa-caroteno, alfa/beta e gama tocoferol, vitamina E e vitamina D. As metodologias aqui utilizadas foram propostas por: Lam et al. (1984); Manz \& Philip (1981); Strhecher \& Henning (1967); Wills et al. (1977); Carvalho et al. (1991) e Bui (1987). Os aminoácidos analisados foram ácido aspártico, treonina, serina, ácido glutâmico, prolina, glicina, alanina, cistina, valina, metionina, isoleucina, leucina, tirosina, fenilalanina, lisina, histidina, triptofano e arginina.

e) Análises bromatológicas: A análise bromatológica compreendeu a determinação de matéria seca, proteína, extrato etéreo (gordura), fibra, cinza, fibra detergente neutra (FDN) e fibra detergente ácida (FDA). Esta análise foi feita conforme metodologia descrita pela AOAC (1990).

f) Análise de energia metabolizável: Nos ensaios para determinação da Energia Metabolizável, seguiram-se os procedimentos da Metodologia Tradicional de Coleta Total com Galos descrita por Sibbald (1976).

g) Análise microbiológica: Analisaram-se os principais microrganismos patogênicos, principalmente para a avicultura, tais como Salmonella, Enterobactérias (E. coli), bolores e leveduras. A metodologia utilizada foi a publicada no DOESP (1991).

\section{Formulação da ração}

Utilizou-se, para formulação da ração, o software Super-
Crac, específico para a formulação de rações para animais de confino.

Este software contêm os dados relativos às exigências nutricionais para as diferentes fases de vida de diversos animais criados em confinamento, além da composição nutricional de um grande número de ingredientes utilizados no arraçoamento. A partir desses dados e com a inclusão dos dados da caracterização nutritiva do IRRA, foi possível, ao software, determinar a porcentagem de inclusão do IRRA, em uma ração formulada com mais dois outros ingredientes muito utilizados no arraçoamento animal, como o farelo de milho e o farelo de soja. Assim, foi possível, também, estabelecer as porcentagens a serem testadas do IRRA para os frangos de corte e elaborar uma ração equilibrada, tanto nutritiva quanto energeticamente.

\section{Preparo da ração}

A ração foi preparada na fábrica de ração do Campus USP - Pirassununga, na qual foram adquiridos todos os ingredientes utilizados, como farelo de milho, farelo de soja (tostado), fosfato bicálcico (27\% de fósforo e 19\% de cálcio), calcário calcítico, sal comum e suplemento de vitaminas e micro minerais para frangos de corte. O suplemento utilizado foi o da marca Duramix, cuja composição é mostrada na Tabela 1. Inicialmente, o procedimento de mistura dos componentes envolveu a pesagem e, depois, a homogeneização, em misturador automático.

Tabela 1. Composição do suplemento vitamínico e mineral utilizado na formulação das rações

\begin{tabular}{lcc}
\hline \multicolumn{1}{c}{ Componentes } & Valores & Unidade \\
\hline Vitamina A & 2.000 .000 & $\mathrm{Ul}$ \\
\hline Vitamina B1 & 500 & $\mathrm{mg}$ \\
\hline Vitamina B2 & 840 & $\mathrm{mg}$ \\
\hline Vitamina B6 & 500 & $\mathrm{mg}$ \\
\hline Vitamina B12 & 2.000 & $\mathrm{mcg}$ \\
\hline Vitamina D3 & 370.000 & $\mathrm{UI}$ \\
\hline Vitamina E & 4.200 & $\mathrm{mg}$ \\
\hline Vitamina K3 & 500 & $\mathrm{mg}$ \\
\hline Ácido Patotênico & 2.500 & $\mathrm{mg}$ \\
\hline Ácido Fólico & 80 & $\mathrm{mg}$ \\
\hline Biotina & 35 & $\mathrm{mg}$ \\
\hline Colina & 120.000 & $\mathrm{mg}$ \\
\hline Niacina & 6.000 & $\mathrm{mg}$ \\
\hline Antioxidante & 150 & $\mathrm{mg}$ \\
\hline Metionina & 200.000 & $\mathrm{mg}$ \\
\hline Agente Anticoccidiano & 334 & $\mathrm{mg}$ \\
\hline Promotor de Crescimento & 2.000 & $\mathrm{mg}$ \\
\hline Manganês (Mn) & 8.400 & $\mathrm{mg}$ \\
\hline Ferro (Fe) & 6.700 & $\mathrm{mg}$ \\
\hline Zinco (Zn) & 6.000 & $\mathrm{mg}$ \\
\hline Cobre (Cu) & 1.000 & $\mathrm{mg}$ \\
\hline lodo (I) & 70 & $\mathrm{mg}$ \\
\hline Selênio (Se) & 27 & $\mathrm{mg}$ \\
\hline
\end{tabular}




\section{Teste com os frangos de corte}

O teste do IRRA em frangos de corte foi efetuado nas dependências do Departamento de Produção Animal, Campus USP, Pirassununga. Para tanto, foram elaborados 6 tipos de ração para a fase inicial de vida dos frangos (0-21 dias, Tabela 2) e 6 tipos para a fase final (22-42 dias, Tabela 2), sendo que uma delas se refere ao controle e foi denominada C. Em todas as rações, o nível de proteína e de energia foi equilibrado em associação com o farelo de milho, farelo de soja e complementos como o fosfato bicálcico (fósforo e cálcio); calcáreo calcítico (cálcio); sal comum (sódio); DL-metionina (aminoácido metionina); óleo de soja (energia) e suplemento vitamínico e mineral (vitaminas e minerais).

As instalações utilizadas foram: um galpão e 3 baterias com 10 gaiolas cada uma, com $25 \mathrm{~cm}$ de altura por $100 \mathrm{~cm}$ de largura e $100 \mathrm{~cm}$ de comprimento, conforme mostra a Figura 2. A duração do teste foi de 6 semanas (42 dias), utilizando-se frangos de corte da linhagem Hubbard. Todos os pintos utilizados no teste apresentavam 1 dia de vida e foram vacinados contra a doença Marek e, após o $9^{\circ}$ dia de vida, vacinados contra New Castle.

As aves foram distribuídas em 6 lotes distintos: C (controle); R-5; R-10, R-15, R-20 e R-25, com 5 repetições de 10 frangos por lote.

Diariamente era feita a troca de água, com lavagem completa dos bebedouros. No caso dos comedouros, a ração remanescente de um dia para o outro era completada durante cada manhã e bem misturada com a anterior, para

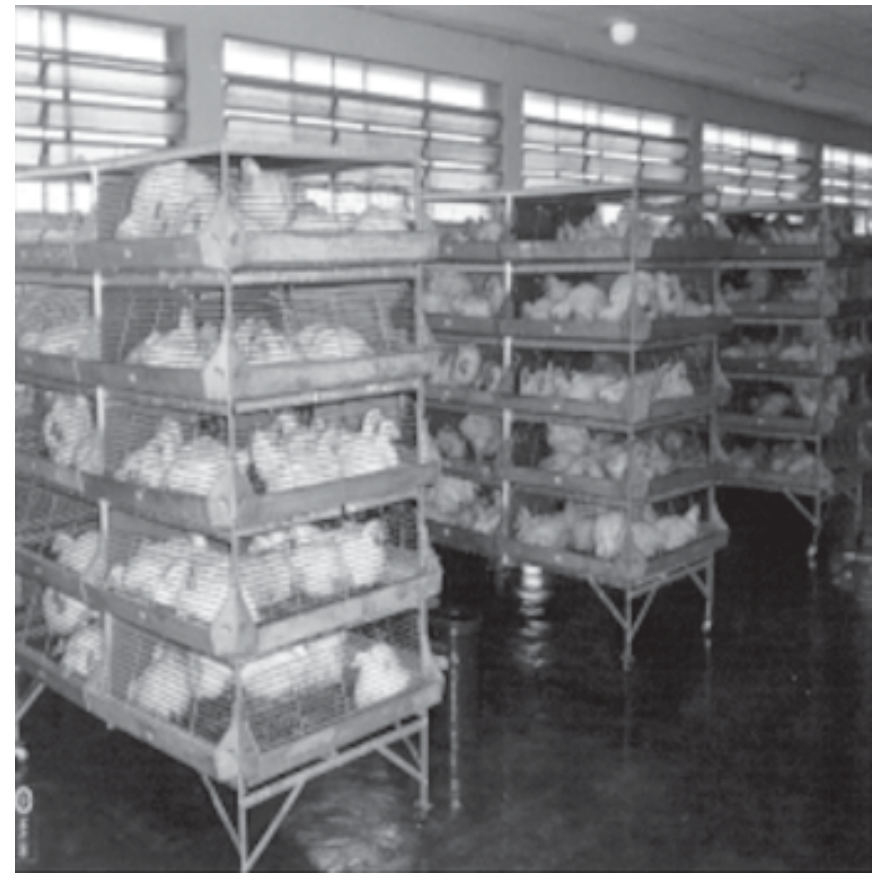

$\overline{\text { Figura 2. Gaiolas utilizadas nos testes realizados com os frangos de corte }}$

garantir a uniformidade dos nutrientes de ambas e promover o estímulo das aves quanto à ração. Ao ser detectada alguma morte, anotavam-se o peso e o lote aos quais pertencia a ave.

Tabela 2. Composição percentual das rações formuladas para a fase inicial (0-21 dias) e final (22-42 dias) de vida dos frangos de corte

\begin{tabular}{|c|c|c|c|c|c|c|c|c|c|c|c|c|}
\hline \multirow[t]{2}{*}{ Ingredientes } & \multicolumn{6}{|c|}{ Composição das Rações (\%) - Fase Inicial } & \multicolumn{6}{|c|}{ Composição das Rações (\%) - Fase Final } \\
\hline & Controle & R-5 & R-10 & R-15 & $\mathrm{R}-20$ & $\mathrm{R}-25$ & Controle & R-5 & R-10 & R-15 & R-20 & R-25 \\
\hline IRRA & 0,0 & 5,0 & 10 & 15 & 20 & 25 & 0,0 & 5,0 & 10 & 15 & 20 & 25 \\
\hline Farelo de milho & 53,09 & 49,49 & 47,36 & 42,08 & 38,37 & 34,67 & 57,05 & 53,34 & 49,63 & 45,93 & 42,22 & 38,52 \\
\hline Farelo de soja & 40,54 & 39,85 & 37,94 & 38,31 & 37,54 & 36,77 & 34,32 & 33,55 & 32,78 & 32,02 & 31,25 & 30,48 \\
\hline Óleo de soja & 2,40 & 2,03 & 1,61 & 1,28 & 0,91 & 0,54 & 5,05 & 4,67 & 4,30 & 3,93 & 3,56 & 3,19 \\
\hline Fosfato bicálcico & 1,71 & 1,71 & 1,65 & 1,69 & 1,68 & 1,66 & 1,60 & 1,58 & 1,57 & 1,56 & 1,55 & 1,54 \\
\hline Calcário calcítico & 1,09 & 0,94 & 0,76 & 0,63 & 0,47 & 0,31 & 1,09 & 0,94 & 0,78 & 0,62 & 0,47 & 0,31 \\
\hline Sal comum & 0,50 & 0,31 & 0,30 & 0,31 & 0,32 & 0,32 & 0,33 & 0,33 & 0,33 & 0,33 & 0,34 & 0,34 \\
\hline Suplemento vit. min. & 0,50 & 0,50 & 0,49 & 0,50 & 0,50 & 0,50 & 0,50 & 0,50 & 0,50 & 0,50 & 0,50 & 0,50 \\
\hline DL - metionina & 0,18 & 0,19 & 0,19 & 0,21 & 0,22 & 0,23 & 0,08 & 0,09 & 0,10 & 0,11 & 0,11 & 0,13 \\
\hline Total (\%) & 100 & 100 & 100 & 100 & 100 & 100 & 100 & 100 & 100 & 100 & 100 & 100 \\
\hline \multicolumn{7}{|c|}{ Composição Calculada (\%) } & \multicolumn{6}{|c|}{ Composição Calculada (\%) } \\
\hline Proteína bruta (\%) & 22,5 & 22,5 & 22,5 & 22,5 & 22,5 & 22,5 & 20 & 20 & 20 & 20 & 20 & 20 \\
\hline EM $\left(\mathrm{kcal} \mathrm{kg}^{-1}\right)$ & 2950 & 2950 & 2950 & 2950 & 2950 & 2950 & 3150 & 3150 & 3150 & 3150 & 3150 & 3150 \\
\hline Cálcio (\%) & 0,950 & 0,950 & 0,950 & 0,950 & 0,950 & 0,950 & 0,900 & 0,900 & 0,900 & 0,900 & 0,900 & 0,900 \\
\hline Fibra (\%) & 4,246 & 4,084 & 3,923 & 3,761 & 3,599 & 3,437 & 3,953 & 3,792 & 3,630 & 3,468 & 3,306 & 3,144 \\
\hline Fósforo total (\%) & 0,676 & 0,680 & 0,684 & 0,688 & 0,692 & 0,695 & 0,630 & 0,633 & 0,637 & 0,641 & 0,645 & 0,649 \\
\hline Fósforo disponível (\%) & 0,430 & 0,430 & 0,430 & 0,430 & 0,430 & 0,430 & 0,400 & 0,400 & 0,400 & 0,400 & 0,400 & 0,400 \\
\hline Gordura (\%) & 5,363 & 5,230 & 5,098 & 4,964 & 4,832 & 4,699 & 8,152 & 8,019 & 7,886 & 7,754 & 7,620 & 7,488 \\
\hline Ácido linolêico (\%) & 2,415 & 2,147 & 1,879 & 1,611 & 1,342 & 1,074 & 3,861 & 3,593 & 3,324 & 3,056 & 2,788 & 2,520 \\
\hline Lisina (\%) & 1,223 & 1,219 & 1,214 & 1,210 & 1,206 & 1,201 & 1,061 & 1,057 & 1,053 & 1,048 & 1,044 & 1,040 \\
\hline Metionina (\%) & 0,514 & 0,521 & 0,527 & 0,534 & 0,540 & 0,547 & 0,384 & 0,390 & 0,397 & 0,404 & 0,410 & 0,417 \\
\hline Metionina + cistina (\%) & 0,874 & 0,874 & 0,874 & 0,874 & 0,874 & 0,874 & 0,710 & 0,710 & 0,710 & 0,710 & 0,710 & 0,710 \\
\hline Treonina (\%) & 0,863 & 0,858 & 0,853 & 0,848 & 0,843 & 0,838 & 0,770 & 0,766 & 0,760 & 0,756 & 0,751 & 0,745 \\
\hline Triptofano (\%) & 0,298 & 0,291 & 0,283 & 0,275 & 0,267 & 0,259 & 0,262 & 0,254 & 0,246 & 0,238 & 0,231 & 0,223 \\
\hline Xantofila (\%) & 13,298 & 12,372 & 11,445 & 10,519 & 9,593 & 8,666 & 14,261 & 13,335 & 12,408 & 11,482 & 10,556 & 9,629 \\
\hline Sódio (\%) & 0,170 & 0,170 & 0,170 & 0,170 & 0,170 & 0,170 & 0,173 & 0,173 & 0,173 & 0,173 & 0,173 & 0,173 \\
\hline
\end{tabular}




\section{Avaliação do desempenho dos frangos de corte}

$\mathrm{Na}$ avaliação do desempenho das aves, coletaram-se os dados relativos à pesagem da ração e das aves, o que é denominado controle, que era feito semanalmente e anotadas, inclusive, as mortes ocorridas naquele período, data e peso.

Através dos dados do controle foram calculados o Consumo de Ração (CR), Ganho de Peso (GP) e a Conversão Alimentar (CA) para cada lote. Esses índices foram utilizados para se avaliar os efeitos da adição da ração de lixo sobre o desempenho das aves no teste e a mortalidade ocorrida.

\section{a) Tratamento estatístico dos dados}

Para o experimento com frangos de corte utilizou-se da Análise de Variância e do Teste Qui-Quadrado.

Com a análise de variância, verificou-se se havia diferença significativa entre o desempenho do lote controle com os demais lotes que tinham inclusão do IRRA, enquanto o teste Qui-Quadrado foi utilizado para se investigar se havia diferença significativa entre as proporções de mortalidade e sobrevivência dos lotes.

\section{b) Avaliação do custo de produção do IRRA}

O custo final de produção do IRRA é aqui representado pelo consumo de energia gasto por cada aparelho, durante o processamento (triturador, autoclave e estufa com ventilação forçada) e o gasto com transporte (combustível) envolvido na coleta dos resíduos.

- Gastos com transporte (combustível)

Esses custos se referiram ao gasto de combustível de uma pick-up para percorrer o trajeto USP-Bairro Santa FelíciaUSP, de aproximadamente $16 \mathrm{~km}$.

- Gastos no processamento dos resíduos

O processamento dos resíduos envolveu trituração, autoclavagem, secagem em estufa com ventilação forçada e, finalmente, uma retrituração das pequenas bolotas rígidas, formadas no decorrer da secagem.

Para facilitar os cálculos de energia gasta em cada aparelho, o consumo de energia foi feito para um volume de $25 \mathrm{~kg}$ de resíduos, ideal para que a massa produzida na trituração fosse dividida em 2 porções iguais de $12,5 \mathrm{~kg}$ na autoclavagem, facilitando a eficiência do processo. O consumo de energia foi calculado conforme a fórmula (Tipler, 1981):

$$
\mathrm{C}=\mathrm{P} . \mathrm{T}
$$

Sendo C o consumo de energia em KWh, $\mathrm{P}$ a potência do aparelho e $\mathrm{T}$ o tempo em horas

I) Trituração: A trituração de $25 \mathrm{~kg}$ de resíduos foi feita em um triturador de $3 \mathrm{cv}$ de potência $(2.206,5 \mathrm{~W})$ por um período aproximado de $25 \mathrm{~min}$.

II) Autoclavagem: Os resíduos foram autoclavados em um autoclave de 45 L com potência de 3000 W; assim, 25 kg de resíduos já triturados eram divididos em dois volumes de $12,5 \mathrm{~kg}$ e autoclavado, cada um deles, a uma temperatura de $121{ }^{\circ} \mathrm{C}$ por $15 \mathrm{~min}$. O tempo gasto pelo aparelho para atingir essa temperatura na primeira autoclavagem, foi de 10 min e nas autoclavagens subsequentes, era de aproximadamente 5 min.

III) Secagem em estufa com ventilação forçada: A es- tufa com ventilação forçada utilizada foi a de modelo 320/3, voltagem $220 \mathrm{~V}$, marca FANEM, com diâmetro interno de $60 \mathrm{~cm}$ (profundidade) x $50 \mathrm{~cm}$ (altura) x $50 \mathrm{~cm}$ (largura). O espaço interno oferecido por essa estufa permitiu utilizar-se, nas 3 prateleiras disponíveis, 6 bandejas de plástico com $14 \mathrm{~cm}$ (comprimento), $10 \mathrm{~cm}$ (largura) e $5 \mathrm{~cm}$ (altura). Em cada bandeja o volume adequado observado para secagem foi de $12 \mathrm{~kg}$ de material.

A uma potência de $2000 \mathrm{~W}$, a estufa operou durante $24 \mathrm{~h}$ para cada material, ligada e desliga através de termostato. De início, o tempo requerido para atingir os $60{ }^{\circ} \mathrm{C}$ no interior da estufa com as 6 bandejas de material foi de aproximadamente 30 min. Levando-se em consideração que é praticamente impossível se obter o cálculo exato do consumo de energia pela estufa durante o seu funcionamento, considerou-se que depois de atingir a temperatura de $60{ }^{\circ} \mathrm{C}$, a estufa estaria trabalhando com consumo zero de energia, funcionando apenas o sistema de ventilação, cujo gasto de energia é mínimo.

IV) Trituração das bolotas rígidas: A trituração de mais ou menos $25 \mathrm{~kg}$ de bolotas rígidas de material, durou aproximadamente $10 \mathrm{~min}$. O importante, nesta fase, é observar o momento certo em que as bolotas podem ser trituradas, de forma que não tenham tanta umidade, reduzindo o tempo de trituração.

\section{RESULTADOS E DISCUSSÃO}

Esta seção apresenta os resultados de acordo com as seguintes etapas de trabalho: processamento dos resíduos alimentares; análises químicas e microbiológica e a Avaliação do custo e da viabilidade do IRRA em frangos de corte.

\section{Processamento dos resíduos alimentares}

O grau de umidade da massa de resíduos triturada foi de aproximadamente $80 \%$, o que dificultou o processo de trituração e secagem, motivo pelo qual a secagem dos resíduos foi um processo mais demorado, sendo necessários 3 dias ao sol, antes de serem armazenados. Este elevado grau de umidade foi responsável pela redução do volume após a secagem, de 4 a 5 vezes em relação ao volume inicial. No período chuvoso, este elevado grau de umidade dos resíduos exigiu grande esforço a fim de reduzir a umidade para valores adequados, ou seja, 12 a 13\%; desta forma, o uso de tais resíduos alimentares requer um planejamento adequado quando se pretende utilizar a secagem ao sol, como adicional pois, dependendo da região e da estação do ano, esta pode ser uma etapa trabalhosa. Em relação aos cuidados com a umidade, deve-se evitar a criação de fungos nos resíduos triturados, que pode atingir a produção de micotoxinas, muitas delas altamente tóxicas às aves e ao ser humano (Shephard, 1996).

Para se obter um componente com as características granulométricas e de umidade semelhantes às de um ingrediente de ração, os resíduos alimentares foram triturados, inicialmente, em peneira de $5 \mathrm{~mm}$ de espessura. Como durante o processo de secagem dos mesmos ocorria a formação de bolotas maiores, com regiões úmidas no seu interior, foi necessário fazer-se uma nova trituração, utilizando-se peneira 
de 10 mm. Em virtude desta trituração não propiciar, ainda, uma granulometria fina, adequada para ração, após a secagem dos resíduos triturados, o material foi novamente triturado, desta vez em peneira de $3 \mathrm{~mm}$. É importante notar que as duas últimas triturações foram extremamente rápidas, visto que o material estava com umidade reduzida.

Após as triturações, obteve-se um produto final denominado Ingrediente de Ração de Resíduos Alimentares (IRRA) com ótimo aspecto, odor e granulometria, além de aparência bastante similar à de uma ração comercial. Deste produto foram retiradas amostras e enviadas aos laboratórios especializados, para a execução das análises químicas e microbiológicas.

\section{Análises bromatológicas}

As análises bromatológicas e de energia metabolizável (Tabela 3), mostraram que o IRRA, quando comparado ao farelo de milho e ao farelo de soja descrito por Fialho \& Albino (1983) e NRC (1994), continha fração elevada de lipídios (extrato etéreo). A quantidade de proteína encontrada no IRRA foi próxima à do farelo de milho, tal qual o valor de energia metabolizável. A quantidade de fibras beirou à do farelo de soja.

Apesar de apresentar valores próximos ou superiores àqueles encontrados no farelo de milho e no farelo de soja, o IRRA, quando utilizado na alimentação das aves em uma mistura com outros ingredientes, fez, por algum motivo com que elas consumissem mais ração. Uma das razões pode ter sido a deficiência para as vitaminas analisadas, muito baixas quando comparadas as vitaminas encontradas no farelo de milho e no farelo de soja. Esta deficiência pode ser devida ao processo térmico empregado no tratamento dos resíduos.

O IRRA não apresentou micotoxinas (aflatoxinas), metais pesados, pesticidas organoclorados ou microrganismos patogênicos (Salmonella, E. coli, bolores e leveduras), o que permitiu ser utilizá-lo na alimentação de frangos de corte, sem prejuízos sobre a saúde das aves em relação a tais componentes tóxicos.

A composição de aminoácidos do IRRA (Tabela 4) se assemelha mais ao farelo de milho que ao farelo de soja, porque a composição de proteínas de ambos foi bastante semelhante e menor que a do farelo de soja. Por outro lado, a composição de minerais apresentou semelhança apenas quanto ao fósforo disponível e ao potássio, que se mostraram próximos ao farelo de soja. A quantidade de cálcio ficou acima do encontrado para o farelo de milho e o farelo de soja, en-

Tabela 3. Resultado da análise bromatológica do IRRA comparada com o farelo de milho e o farelo de soja, descritos por Fialho \& Albino (1983) e NRC (1994)

\begin{tabular}{lccc}
\hline \multicolumn{1}{c}{ Nutrientes } & IRRA & Farelo de Milho & Farelo de Soja \\
Proteína (\%) & 12,95 & 8,5 & 44 \\
Extrato etério (\%) & 8,59 & 4,97 & 0,79 \\
Ácido linolêico (\%) & 0 & 1,84 & 0,4 \\
Fibras (\%) & 8,65 & 3,02 & 7 \\
Matéria mineral (\%) & 7,99 & - & - \\
Energia metabolizável $\left({\left.\mathrm{kcal} \mathrm{kg}^{-1}\right)}\right.$ & 3.483 & 3.416 & 2.240 \\
\hline
\end{tabular}

quanto os demais minerais permaneceram abaixo da composição presente no farelo de milho e no farelo de soja, como mostra a Tabela 4.

Avaliação da viabilidade do IRRA em frangos de corte e do custo de produção do IRRA

Os resultados da análise de variância a um nível de significância de $5 \%$, permitiram que as variações significativas existentes entre o lote controle e todos os lotes com adição de IRRA, fossem identificados considerando-se o consumo de ração, ganho de peso e conversão alimentar no decorrer das 6 semanas de experimento com os frangos de corte. Referidas variações se apresentaram acima ou abaixo dos valores registrados para o lote controle, conforme descrito a seguir, para todos os lotes contendo IRRA.

Deste modo e pela análise de variância, o lote R-5 ganhou menos peso na segunda semana de experimento apresentando, por conseqüência, uma conversão alimentar pior. Este ganho de peso e a conversão alimentar foram significativamente maiores na terceira semana, diminuiu na quarta semana, embora não tenha havido variação significativa na quinta semana mas finalizaram significativamente melhores na sexta semana. O consumo de ração, por sua vez, não apresentou diferença significativa em todas as 6 semanas de experimento. Mesmo com as oscilações que ocorreram entre as segunda e quarta semanas, para o ganho de peso e

Tabela 4. Caracterização do IRRA para aminoácidos e minerais em comparação com o farelo de milho e o farelo de soja, descritos por Fialho \& Albino (1983) e NRC (1994)

\begin{tabular}{|c|c|c|c|}
\hline Aminoácidos (\%) & IRRA & Farelo de Milho & Farelo de Soja \\
\hline Arginina & 0,34 & 0,38 & 3,14 \\
\hline Glicina & 0,70 & 0,33 & 1,90 \\
\hline Serina & 0,51 & 0,37 & 2,29 \\
\hline Histidina & 0,33 & 0,23 & 1,17 \\
\hline Isoleucina & 0,45 & 0,29 & 1,96 \\
\hline Leucina & 0,80 & 1,00 & 3,39 \\
\hline Lisina & 0,50 & 0,23 & 2,71 \\
\hline Cistina & 0,10 & 0,17 & 0,64 \\
\hline Metionina & 0,16 & 0,17 & 0,62 \\
\hline Fenilalanina & 0,52 & 0,38 & 2,16 \\
\hline Tirosina & 0,34 & 0,30 & 1,91 \\
\hline Treonina & 0,41 & 0,29 & 1,72 \\
\hline Triptofano & $\mathrm{Nd}$ & 0,06 & 0,74 \\
\hline Valina & 0,57 & 0,40 & 2,07 \\
\hline \multicolumn{4}{|l|}{ Minerais } \\
\hline Fósforo disponível (\%) & 0,40 & 0,27 & 0,55 \\
\hline Cálcio (\%) & 1,30 & 0,02 & 0,29 \\
\hline Potássio (\%) & 0,80 & 0,26 & 1,05 \\
\hline Cloro (\%) & nd & 0,04 & 0,05 \\
\hline Ferro $\left(\mathrm{mg} \mathrm{kg}^{-1}\right)$ & 0,0012 & 45,00 & 120,00 \\
\hline Magnésio (mg kg-1) & 0,00 & 1200 & 2700 \\
\hline Sódio (\%) & 0,0117 & 0,02 & 0,091 \\
\hline Cobre (mg kg-1) & 0,0005 & 3,00 & 22,00 \\
\hline Selênio (mg kg-1) & nd & 0,03 & 0,10 \\
\hline lodo (mg kg-1) & nd & 18,00 & 0,00 \\
\hline Manganês (mg kg-1) & 0,001195 & 7,00 & 29,00 \\
\hline Zinco $\left(\mathrm{mg} \mathrm{kg}^{-1}\right)$ & 0,001612 & 18,00 & 40,00 \\
\hline
\end{tabular}

nd - não detectado 




Figura 3. Efeitos da adição do IRRA sobre o consumo de ração (CR) (kg ave $\left.\mathrm{e}^{-1}\right)$ o ganho de peso (GP) (kg ave-1) e conversão alimentar (CA), para o período de 1-42 dias de experimento

conversão alimentar, nas quinta e sexta semanas tais parâmetros não apresentaram resultado significativamente diferente do lote controle, demonstrando que a adição de $5 \%$ de IRRA na ração final não alterou o desempenho das aves, como ilustrado na Figura 3.

Na segunda semana, o peso do lote R-10 foi inferior, porém ganhou mais peso na terceira semana; na quarta semana ele consumiu menos ração e em conseqüência, novamente o ganho de peso foi menor; na semana seguinte este lote consumiu mais ração, ganhou mais peso e teve melhor conversão alimentar, indicando também que, a partir da quinta semana, os resultados de desempenho das aves foi igual ou melhor que o do controle, apontando para o uso da ração, quanto aos parâmetros analisados, na proporção de 10\%, como ingrediente para ração de frangos de corte, conforme ilustrado na Figura 3.

Para o lote R-15, as aves consumiram menos ração na primeira semana e, logicamente, ganharam menos peso e, portanto, sua conversão alimentar foi pior que a do lote controle; já na terceira semana elas consumiram, outra vez, menos ração e ganharam menos peso, o que também aconteceu na quarta semana, embora na quinta semana tenha havido ganho maior de peso; já na sexta semana as aves consumiram mais ração, ganharam mais peso e apresentaram conversão alimentar melhor que a do lote controle (Figura 3) ou seja, no final do experimento a adição de 15\% de IRRA na ração dos frangos de corte, não afetou o desempenho das aves em relação ao lote controle.

As aves do lote R-20 ganharam mais peso na terceira semana, enquanto que na quarta semana se deu o inverso, isto é, ganharam menos peso e tiveram uma conversão alimentar pior que a do lote controle; Na sexta semana, elas consumiram mais ração, porém a conversão alimentar não indicou diferença significativa em relação ao controle (Figura 3). Novamente, os resultados indicam que, no final do experimento (quinta e sexta semana), a inclusão do IRRA, com $20 \%$ na ração de frangos de corte, não afetou o desempenho das aves.
Tabela 5. Dados sobre a média do CR, GP e CA para a sexta semana de experimento, com os frangos de corte

\begin{tabular}{ccccc}
\hline Lote & IRRA na Ração (\%) & CR (kg ave $\left.\mathbf{~}^{-1}\right)$ & GP $\left(\mathbf{k g ~ a v e}^{-1}\right)$ & CA \\
C & 0 & 0,93 & 0,32 & 2,92 \\
R-5 & 5 & 1,03 & 0,39 & 2,63 \\
R-10 & 10 & 1,04 & 0,38 & 2,78 \\
R-15 & 15 & 1,13 & 0,51 & 2,24 \\
R-20 & 20 & 1,07 & 0,36 & 2,97 \\
R-25 & 25 & 1,09 & 0,38 & 2,95 \\
\hline
\end{tabular}

No lote R-25 as aves ganharam mais peso na terceira semana, na quarta semana houve perda de peso em relação a do lote controle e a conversão alimentar também foi pior, enquanto que na sexta semana as aves apenas consumiram mais ração em relação ao lote controle (Figura 3). Da mesma forma que os lotes anteriores, no final do experimento as aves não apresentaram desempenho diferente em relação ao lote controle, indicando o uso do IRRA em até $25 \%$ na composição da ração para frangos de corte.

De modo geral, todos os lotes com inclusão de IRRA mostraram desempenho igual ou melhor que o do lote controle. Por outro lado, nos lotes com adição de IRRA, as aves consumiram mais ração na sexta semana. Mesmo consumindo mais ração, somente os lotes R-5 e R-15 apresentaram melhor ganho de peso e apenas o lote R-15 teve conversão alimentar melhor na sexta e última semana de estudo.

Os dados das médias do consumo de ração, ganho de peso e conversão alimentar para a sexta semana de experimento, podem ser visualizados na Tabela 5 .

A mortalidade das aves, avaliada para as 6 semanas de teste, foram de 6, 6, 0, 10, 4 e 16\% para os lotes C, R-5, R-10, R15, R-20 e R-25, respectivamente. O maior número de mortes registrado foi para o lote R-25, em que a distribuição das mortes em cada semana (Figura 4) mostrou que, das 8 aves mortas nas 6 semanas de experimento, 5 ocorreram na segunda semana e foram relativos a 3 das 5 repetições do lote.

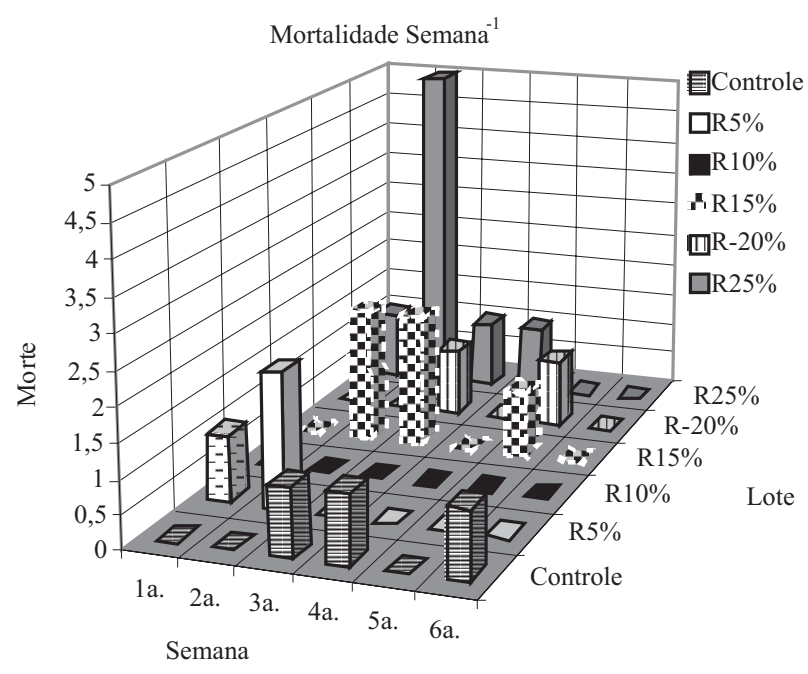

Figura 4. Distribuição semanal das mortes das aves para cada lote, durante o experimento 
Tabela 6. Valores observados e valores esperados de mortalidade para cada lote, no segundo experimento

\begin{tabular}{|cccccccccc}
\hline \multicolumn{1}{c}{ Valores Observados } \\
& Controle & R-5 & R-10 & R-15 & R-20 & R-25 & Total & $\%$ \\
\hline Mortalidade & 3 & 3 & 0 & 5 & 2 & 8 & 21 & 7 \\
\hline Sobreviventes & 47 & 47 & 50 & 45 & 48 & 42 & 279 & 93 \\
\hline Total & 50 & 50 & 50 & 50 & 50 & 50 & 300 & \\
\multicolumn{7}{c}{ Valores Esperados } \\
& Controle & R-5 & R-10 & R-15 & R-20 & R-25 & Total & $\%$ \\
\hline Mortalidade & 3.5 & 3.5 & 3.5 & 3.5 & 3.5 & 3.5 & 21 & 7 \\
\hline Sobreviventes & 46.5 & 46.5 & 46.5 & 46.5 & 46.5 & 46.5 & 279 & 93 \\
\hline Total & 50 & 50 & 50 & 50 & 50 & 50 & 300 & \\
\hline
\end{tabular}

O teste Qui-quadrado mostrou que as proporções de mortalidade e sobrevivência dos lotes (Tabela 6), não apresentaram diferença significativa, exceto para o lote R-25. Este lote, como mencionado, apresentou mortalidade concentrada em 3 das suas repetições durante a segunda semana de experimento, embora não se saiba se, realmente, foi o IRRA ou não o responsável.

Com relação às mortes e embora não comprovado, convém salientar que o IRRA continha uma quantidade de lipídeos bem acima daquela encontrada no farelo de milho. Esses lipídeos podem ter como origem principal, o arroz descartado no lixo, que foi elemento primordial presente nos resíduos estudados; além disso, pode ser que tais lipídeos tenham outras origens e com processamentos diferenciados como, por exemplo, o descarte de sobra de frituras, que pode, de alguma forma, estar relacionado com as mortes ocorridas.

O cálculo de produção do IRRA envolveu os custos de transporte dos resíduos e o gasto de energia no processamento. O custo do transporte ficou em torno de $\mathrm{R} \$ 0,00324$ por kg resíduo transportado. Na autoclavagem foram gastos 2,25 kWh, $1 \mathrm{kWh}$ na estufa com ventilação forçada, $0,5 \mathrm{kWh}$ para trituração de bolotas rígidas e 0,905 kWh para a trituração. Somando-se todos os gastos de energia em $\mathrm{kWh}$ de todas as fases de produção do IRRA, tem-se que o custo final de $1 \mathrm{~kg}$ de IRRA foi de $\mathrm{R} \$ 0,16$, levando-se em consideração o preço de 1999, de combustível e energia utilizados. Este valor está um pouco abaixo $(5,8$ a $11,1 \%)$ do preço do kg do farelo de milho mais utilizado no ramo de arraçoamento comercial, que tem custo variando entre $\mathrm{R} \$ 0,17$ e R\$ 0,18. Levando-se em conta os valores extremos de $11 \%$ de redução de custo para o componente que é adicionado a uma proporção de $25 \%$ (em massa) à ração, o custo final da ração a ser fornecida aos frangos fica reduzido em aproximadamente $3 \%$, quando se considera a escala de trabalho aqui adotada. Escalas maiores devem implicar também em redução maior dos custos, porque os investimentos necessários passam a ser diluídos em uma quantidade maior do componente; além disso, quando se consideram os custos ambientais evitados com o descarte dos resíduos alimentares no lixo, os ganhos com esse tipo de reciclagem se tornam imensuráveis.

\section{Recomendações}

1. Considerando-se a falta de espaço e os sacrifícios ofere- cidos pelas baterias na criação de frangos associados aos possíveis danos sobre as estruturas ósseas e articulações das aves, como mencionado pela literatura (Riddell, 1983; Reece et al, 1971 e Haye \& Simons, 1978), sugere-se que experimentos como este sejam conduzidos em gaiolas maiores ou em piso.

2. Tendo em vista a dificuldade encontrada durante a secagem dos resíduos e se levando em consideração o alto índice inicial de umidade do material (80\%), é de grande valia o desenvolvimento de métodos que permitam uma secagem mais rápida e de custo reduzido, visto que a secagem ao sol utilizada neste trabalho, é um método limitado às estações de estiagem (maio a outubro, no Estado de São Paulo).

\section{CONCLUSÕES}

1. O grau de umidade detectado na massa de resíduos triturada foi de $80 \%$, o que dificultou o processo de trituração e secagem.

2. A reciclagem de resíduos alimentares do lixo domiciliar em um ingrediente para ração de frangos de corte, não gerou nenhum subproduto durante as etapas de processamento.

3. O componente obtido a partir dos resíduos alimentares do lixo domiciliar apresentou características adequadas quanto ao estado físico, odor e granulometria, para consumo avícola.

4. O Ingrediente de Ração de Resíduos Alimentares não apresentou componentes tóxicos, como micotoxinas (aflatoxinas B1, B2, G1 e G2), pesticidas organoclorados, metais pesados $(\mathrm{Pb}, \mathrm{Cd}$, Ni e $\mathrm{Cr}$ ) e microrganismos patogênicos, como Salmonella e E. coli.

5. A caracterização de nutrientes do Ingrediente de Ração de Resíduos Alimentares evidenciou níveis elevados de lipídios e de energia metabolizável, além de se assemelhar, em diversos outros nutrientes, com os encontrados no farelo de milho e farelo de soja, largamente utilizados como matéria-prima para as rações de frangos de corte.

6. Fica comprovada a viabilidade de utilização de resíduos alimentares do lixo domiciliar como um ingrediente na ração de frangos de corte, até à proporção de $20 \%$ de inclusão, considerando-se que se desconhece a causa da concentração das mortes em algumas repetições do lote R-25.

\section{AGRADECIMENTOS}

Os autores são gratos à FAPESP, pelo apoio financeiro (Processos 95-8993-9 e 96-8126-6) que possibilitou a execução do presente trabalho.

Ao CNPq, pela concessão de bolsa no primeiro ano de doutorado.

\section{LITERATURA CITADA}

AOAC - Association of Official Analytical Chemists Official methods of analysis. 12.ed. Washington: District of Columbia. p.44. 1975. 
AOAC - Association of Official Analytical Chemists Official methods of analysis. 14.ed. Washington: District of Columbia. 1984.

AOAC - Association of Official Analytical Chemists Official methods of analysis. 15.ed. Arlington: Distric of Columbia, p.1298. 1990.

Blake, J. P.; Donald, J. O. Alternatives for the disposal of poultry carcasses. Poultry Science, Alabama, v.71, n.7, p.11301135. 1992.

Bui, M. H. Sample preparation and liquid chromatographic determination of vitamin in food products. Journal of the Association of Official Analitical Chemists, Washington, v.70, n.5, p.802-805. 1987.

Carvalho, P. R. N.; Rodriguez-Amaya, D. B.; Collins, C. H. Determinacao de carotenóides e provitamina A por cromatografia liquida de alta eficiência (CLAE). Coletânea do ITAL, Campinas, v.21, p.317-328, 1991.

DOESP Diário Oficial do Estado de São Paulo (10 de abril de 1991) São Paulo, v.108, n.62, p.1-43, Seção 1, Suplemento. 1991.

Fialho, E. T.; Albino, L. F. T. Tabela de composição química e valores energéticos de alimentos para suínos e aves. Concórdia: EMBRAPA-CNPSA, 1983, p.23

Freitas, A. L. S. Caracterização do aqüífero Botucatu na região do lixão de São Carlos, SP. São Carlos: EESC/USP, 1996. 113p. Dissertação Mestrado

Haye, U.; Simons, P. C. M. Twisted legs in broilers. British Poultry Science, Abingdon, United Kingdom. 1978, p.549-557

Jardim, N. S. (org) Lixo municipal: manual de gerenciamento integrado, 1.ed. São Paulo: IPT/CEMPRE 2163. 1995. 370p.

Lam, F. L.; Holcomb, I. J.; Fusari, S. A. Liquid chromatography assay of ascorbic acid, niacinamide, niridoxine, thiamine and riboflavin in multivitamin mineral preparations. Jounal of the Association of Analitical Chemists. Washington DC, v.67, n.5, p.1007-1011, 1984.

Lima, L. M. Q. Tratamento e biorremediação de lixo. São Paulo: Hemus Editora Ltda. 1995. 240p.

Malavolta, E.; Vitti, G. C.; Oliveira, S. A. Avaliação do estado nutricional das plantas. Piracicaba: Associação Brasileira para Pesquisa da Potassa e do Fosfato. 1989. 201p.
Manz, U.; Phillip, A. Method the routine determination of tocopherols in animal feed an human foodstuffs eth the aid of high performance liquid chromatography International Journal for Vitamin and Nutrition Research, Berne. Swiss. v.51, p.342-48. 1981.

NRC National Research Council. Nutrient requirements of poultry. Ninth revised edition, Washington: District of Columbia. 1994. 157p.

Oliveira, A. L. Silagem de aves mortas para a alimentação animal. In: Conferência APINCO de Ciência e Tecnologia Avícolas, 1996, Curitiba. Anais ..., Curitiba: APINCO, 1996. p.85-94.

Reece, F. N.; Deaton, J. W.; May, J. D. Cage versus floor rearing of broiler chickens. Poultry Science, Mississipi, v.50, p.17861798. 1971.

Riddell, C. Pathology of the skeleton and tendons of broiler chickens reared to roaster weights. Avian Diseases. Minneapolis. v.27, n.4, p.950- 62. 1983.

Sabino, M.; Prado, G.; Inomata, E. I.; Pedroso, M. O.; Garcia, R. $\mathrm{V}$. Natural occurence of aflotoxins and zearalenone in maize in Brazil. Part II. Food Additives and Contaminants, v.6, n.3, p.327-331, 1989.

Schalch, V. Produção e características do chorume em processo de decomposição de lixo urbano. São Carlos: EESC/USP. 1984. 103p. Dissertação Mestrado

Shephard, G. S. Worldwide survey of fumonisin contamination of corn and corn-based products. Journal of AOAC International, Gaithersburg, v.79, n.3, p.671-687. 1996.

Sibbald, I. R. A. Bioassay for true metabolizable energy in feedingstuffs. Poultry Science, Champaign, v.55, p.303-308. 1976.

Simabuco, S. M. Determinação de metais pesados a nível de traços em amostras de chorume pela técnica de fluorescência de raios-x por dispersão de energia. In: Congresso Geral de Energia Nuclear. 6. 1996, Rio de Janeiro. Anais. Rio de Janeiro: IPEN, 1996. CD-Rom

Strhecher, R.; Henning, H. M. Analisis de vitaminas: metodos comprobados. Madrid: Paz Montalvo, 1967. 428p.

Tipler, P. A. Física Geral. Rio de Janeiro: Guanabara. 1981. 422p.

Wills, R. B. H.; Shaw, C. G.; Day, W. R. Analysis of water soluble vitamins by high performance liquid chromatography. Journal of Chromatographic Science, New York, v.15, p.262265, 1977. 